\title{
AKTIVASI ZEOLIT DAN KARBON AKTIF DALAM MENURUNKAN KESADAHAN AIR DI KAMPUNG SAPIRIAKOTA MAKASSAR
}

\author{
Sudarni ${ }^{1}$, Haderiah ${ }^{2}$ \\ 1,2Poltekkes Kemenkes Makassar \\ sudarnisalama@gmail.com
}

\begin{abstract}
Water with poor quality is caused by pollution of chemical parameters. The chemical parameters in question are water hardness. one method that can be used is water treatment in a simple way, namely processing by filtration (filtering) using zeolite filtering media, activated carbon, and a combination of zeolite media - activated carbon. This study aims to determine the difference in effectiveness of zeolite and activated carbon filtration media in reducing hardness levels in dug well water. This type of research was quasi-experimental with a pretest-posttest design with control group design and carried out three times replication or repetition. Data from laboratory research and examination results were then processed and analyzed using one way ANOVA statistical tests. The average yield of hardness levels $\left(\mathrm{CaCO}_{3}\right)$ in the dug wells before processing was $160.24 \mathrm{mg} / \mathrm{I}$ and after processing using zeolite media was $76.82 \mathrm{mg} / \mathrm{I}$ with an effectiveness of $52.05 \%$, using activated carbon media was $74,86 \mathrm{mg} / \mathrm{I}$ with the effectiveness of $53,27 \%$, processing using zeolite combination of activated carbon media was $109.75 \mathrm{mg} / \mathrm{I}$ with the effectiveness of $31.5 \%$. The results of the one way ANOVA statistical test showed that there were significant differences in hardness levels on the filter media used with the sig value. $0.00<0.05$. Zeolite filter media can reduce hardness $\left(\mathrm{CaCO}_{3}\right)$ better than activated carbon media and combination media in reducing hardness $\left(\mathrm{CaCO}_{3}\right)$. For the community, this simple water treatment can be applied to the household scope and for researchers to be able to continue the research by making a variation of the time I live or the thickness of the media used.
\end{abstract}

Keywords : Filtration, Zeolite, Active Kabon, Hardness $\left(\mathrm{CaCO}_{3}\right)$

\begin{abstract}
ABSTRAK
Air dengan kualitas buruk salah satunya disebabkan oleh pencemaran parameter kimia. Parameter kimia yang dimaksud yaitu kesadahan air. salah satu cara yang dapat digunakan adalah pengolahan air dengan cara sederhana, yaitu pengolahan secara filtrasi (penyaringan) dengan menggunakan media penyaringan zeolit, karbon aktif, dan kombinasi media zeolit - karbon aktif. Penelitian ini bertujuan untuk mengetahui perbedaan efektivitas media filtrasi zeolit dan karbon aktif dalam menurunkan kadar kesadahan pada air sumur gali. Jenis penelitian ini adalah eksperimental semu dengan rancangan pretest-posttest with control group design dan dilakukan sebanyak tiga kali replikasi atau pengulangan. Data hasil penelitian dan pemeriksaan Laboratorium kemudian diolah dan dianalisis menggunakan uji statistik one way anova. Hasil rata-rata kadar kesadahan $\left(\mathrm{CaCO}_{3}\right)$ pada sumur gali sebelum pengolahan adalah 160,24 mg/l dan setelah pengolahan dengan menggunakan media zeolit adalah 76,82 mg/l dengan efektivitas $52,05 \%$, dengan menggunakan media karbon aktif adalah $74,86 \mathrm{mg} / \mathrm{l}$ dengan efektivitas $53,27 \%$, pengolahan dengan menggunakan media kombinasi zeolit - karbon aktif adalah 109,75 mg/l dengan efektivitas 31,5\%. Hasil uji statistik one way anova menunjukkan ada perbedaan yang signifikan untuk kadar kesadahan pada media filter yang digunakan dengan nilai sig. $0,00<0.05$. Media filter zeolit dapat menurunkan kesadahan $\left(\mathrm{CaCO}_{3}\right)$ lebih baik dari media karbon aktif dan media kombinasi dalam menurunkan kadar kesadahan $\left(\mathrm{CaCO}_{3}\right)$. Bagi masyarakat, pengolahan air sederhana ini dapat diterapkan pada lingkup rumah tangga dan bagi peneliti agar dapat melanjutkan penelitian tersebut dengan membuat variasi watku tinggal atau dengan ketebalan media yang digunakan.
\end{abstract}

Keyword : Filtrasi, Zeolit, Karbon Aktif, Kesadahan $\left(\mathrm{CaCO}_{3}\right)$

\section{PENDAHULUAN}

Air merupakan salah satu sumberdaya alam yang memiliki fungsi sangat penting bagi kehidupan dan perikehidupan manusia, serta untuk memajukan kesejahteraan umum sehingga merupakan modal dasar dan faktor utama pembangunan. Air juga merupakan komponen lingkungan hidup yang penting bagi kelangsungan hidup manusia dan makhluk hidup lainnya. Itu bisa dilihat dari fakta bahwa 70 persen permukaan bumi tertutup air dan dua per tiga tubuh manusia terdiri dari air. (Asmadi et. al. 2011)

Akhir-akhir ini sulit untuk mendapatkan air bersih. Penyebab susahnya mendapatkan air bersih adalah adanya pencemaran air yang disebabkan oleh limbah industri, rumah tangga, dan limbah pertanian. Selain itu adanya pembangunan dan penjarahan hutan merupakan penyebab berkurangnya kualitas mata air dari pegunungan karena banyak bercampur dengan lumpur yang terkikis terbawa aliran air sungai. Akibatnya, air bersih kadang menjadi barang langka. (Alamsyah, 2007)

Air dengan kualitas buruk salah satunya disebabkan oleh pencemaran parameter kimia. Parameter kimia yang dimaksud yaitu kesadahan air. Kesadahan dalam air terutama disebabkan oleh keberadaan $\mathrm{Ca}^{2+}$ dan $\mathrm{Mg}^{2+}$ baik dalam bentuk kesadahan karbonat yang tersusun atas garam bikarbonat $\left(\mathrm{Ca}\left(\mathrm{HCO}_{3}\right)^{2}\right.$ dan $\left.\mathrm{Mg}\left(\mathrm{HCO}_{3}\right)^{2}\right)$ dan karbonat $\left(\mathrm{CaCO}_{3}\right.$ dan $\left.\mathrm{MgCO}_{3}\right)$ serta kesadahan non karbonat yang meliputi $\mathrm{CaSO}_{4}$, $\mathrm{CaCl}_{2}, \mathrm{MgSO}_{4}$, dan $\mathrm{MgCl}_{2}$ (National Drinking Water Clearinghouse, 1999 dalam Mulyani, 2017) Kesadahan disebabkan karena air yang mengandung mineral dari kation logam bervalensi dua dalam jumlah yang berlebihan. Biasanya yang sering menimbulkan kesadahan adalah kation $\mathrm{Ca}^{++}$dan $\mathrm{Mg}^{++}$. Kesadahan total adalah 
Jurnal Sulolipu : Media Komunikasi Sivitas Akademika dan Masyarakat

Vol. 20 No.12020

e-issn : 2622-6960, p-issn : 0854-624X

kesadahan yang disebebkan oleh $\mathrm{Ca}^{++}$dan $\mathrm{Mg}^{++}$ secara bersama-sama.(Effendi, 2012)

Penelitian ini menggunakan media zeolit dan arang aktif/ karbon aktif. Zeolit memiliki struktur molekul yang unik, yaitu atom silikon dikelilingi oleh 4 atom oksigen sehingga membentuk semacam jaringan dengan pola yang teratur. Karbon aktif dipilih karena memiliki sejumlah sifat kimia maupun fisika yang menarik, di antaranya mampu menyerap zat organik maupun anorganik, dapat berlaku sebagai penukar kation, dan sebagai katalis untuk berbagai reaksi.

\section{BAHAN DAN METODE}

\section{Lokasi Penelitian}

Lokasi pengambilan sampel ini dilakukan di Kampung Sapiria, Kelurahan Lembo, Kecamatan Tallo, Kota Makassar, dan lokasi penelitian dilakukan di Workshop Jurusan Kesehatan Lingkungan Poltekkes Makassar.Dan lokasi untuk melakukan pemeriksaan sampel di Laboratorium Jurusan Kesehatan Lingkungan Poltekkes Makassar.

\section{Desain dan Variabel Penelitian}

a) Desain Penelitian

Penelitian yang dilakukan merupakan penelitian eksperimen semu (Quasi Experiment)

Rancangan atau desian penelitian yang digunakan adalah pretest-posttest with control group design yaitu unit percobaan dikenakan perlakuan dengan dua kali pengukuran.Pengukuran pertama dilakukan sebelum perlakuan dilaksanakan dan pengukuran kedua dilakukan sesudah perlakuan dilaksanakan.

Penelitian ini menggunakan desain berupa alat penyaringan yang dirancang untuk penelitian dengan media zeolit dan karbon aktif. Pembuatan alat filtrasi dengan menggunakan bahan atau media yaitu zeolit dan karbon aktif manakala alat yang dibutuhkan yaitu bak reservoir, pipa, sambungan pipa, stop kran, dan keran air.

Desain alat yang dibuat terdiri dari bak reservoir, pipa pengairan, tabung kontrol, tabung media zeolit dengan ketebalan $60 \mathrm{~cm}$, tabung media karbon aktif dengan ketebalan $60 \mathrm{~cm}$, dan tabung media kombinasi dengan ketebalan $60 \mathrm{~cm}$ masing-masing lapisan
$30 \mathrm{~cm}$ dan masing-masing tabung memiliki outlet.

\section{Populasi dan Sampel}

Populasi dan penelitian ini adalah air sumur gali yang berada di Kampung Sapiria, Kelurahan Lembo, Kecamatan Tallo, Kota Makassar.

Air sumur gali yang akan digunakan sebagai sampel sebanyak 20 liter untuk satu kali perlakuan dengan pengulangan sebanyak tiga kali, maka jumlah sampel untuk satu kali perlakuan termasuk pengulangan sebanyak 60 liter dan untuk kontrol termasuk pengulangan membutuhkan air sebanyak 60 liter. Sehingga jumlah total sampel air yang digunakan sebanyak 120 liter.

\section{Pengumpulan Data}

Data primer diperoleh dari hasil pemeriksaan sampel air baik sampel pretest atau sebelum perlakuan maupun sampel posttest setelah perlakuan di Laboratorium Kimia Jurusan Kesehatan Lingkungan Poltekkes Makassar.Data sekunder diperoleh dari penelusuran perpustakaan berupa bukubuku, jurnal, karya tulis ilmiah, dan sebagainya.

\section{Analisa Data}

Data yang diperoleh berdasarkan hasil pemeriksaan laboratorium kemudian diolah dengan menggunakan komputer/kalkulator.Data dianalisa menggunakan uji analisa anova satu arah dan data yang telah dianalisa disajikan dalam bentuk tabel dengan menggunakan aplikasi SPSS.

\section{A. HASIL}

Tabel 1

Rata-rata Hasil Pemeriksaan Kesadahan $\left(\mathrm{CaCO}_{3}\right)$ Air Sumur Gali di Kampung Sapiria Kecamatan Tallo Kota Makassar

\begin{tabular}{c|c|c|c|c}
\hline \multirow{2}{*}{$\begin{array}{c}\text { Sebelum } \\
\text { Perlakuan }\end{array}$} & \multirow{2}{*}{$\begin{array}{c}\text { Replik } \\
\text { asi }\end{array}$} & \multicolumn{2}{|c|}{$\begin{array}{c}\text { Kadar } \\
\text { Kesadahan } \\
\text { (CaCO3) }\end{array}$} & \multirow{2}{*}{$\begin{array}{c}\text { Efektivitas } \\
\text { Penurunan } \\
\text { (\%) }\end{array}$} \\
\cline { 3 - 4 } & & \multicolumn{2}{|c|}{$\begin{array}{c}\text { Setelah } \\
\text { Perlakuan }\end{array}$} & \\
\cline { 3 - 4 } & Kontrol & Zeolit & Zeolit \\
\hline \multirow{2}{*}{$\mathbf{1 6 0 , 2 4}$} & 1 & 109,76 & 77,92 & 51,37 \\
\cline { 2 - 4 } & 2 & 113,05 & 75,73 & 52,74 \\
\hline \multicolumn{2}{c|}{ Rata-Rata } & 115,61 & 76,82 & 52,05 \\
\hline
\end{tabular}


Jurnal Sulolipu : Media Komunikasi Sivitas Akademika dan Masyarakat

Vol. 20 No.12020

e-issn : 2622-6960, p-issn : 0854-624X

Sumber : data primer

Pada penelitian ini media yang digunakan

Tabel 2

Rata-rata Hasil Pemeriksaan Kesadahan $\left(\mathrm{CaCO}_{3}\right)$ Air Sumur Gali di Kampung Sapiria Kecamatan Tallo Kota Makassar

\begin{tabular}{|c|c|c|c|c|}
\hline \multirow{3}{*}{$\begin{array}{l}\text { Sebelum } \\
\text { Perlakuan }\end{array}$} & \multirow{3}{*}{$\begin{array}{l}\text { Replik } \\
\text { asi }\end{array}$} & \multirow{2}{*}{\multicolumn{2}{|c|}{$\begin{array}{c}\text { Kadar Kesadahan } \\
(\text { CaCO3) }\end{array}$}} & \multirow{3}{*}{$\begin{array}{c}\begin{array}{c}\text { Efektivitas } \\
\text { Penuruna } \\
\text { n (\%) }\end{array} \\
\begin{array}{c}\text { Karbon } \\
\text { Aktif }\end{array}\end{array}$} \\
\hline & & & & \\
\hline & & Kontrol & $\begin{array}{l}\text { Karbo } \\
\text { n Aktif }\end{array}$ & \\
\hline \multirow{3}{*}{160,24} & 1 & 109,76 & 95,32 & 40,51 \\
\hline & 2 & 113,05 & 73,82 & 53,93 \\
\hline & 3 & 124,02 & 55,45 & 65,39 \\
\hline \multicolumn{2}{|c|}{ Rata-Rata } & 115,61 & 74,86 & 53,27 \\
\hline
\end{tabular}

Tabel 3

Rata-rata Hasil Pemeriksaan Kesadahan $\left(\mathrm{CaCO}_{3}\right)$ Air Sumur Gali di Kampung Sapiria Kecamatan Tallo Kota Makassar

\begin{tabular}{|c|c|c|c|c|}
\hline \multirow{3}{*}{$\begin{array}{l}\text { Sebelum } \\
\text { Perlakuan }\end{array}$} & \multirow{3}{*}{ Replikasi } & \multirow{2}{*}{\multicolumn{2}{|c|}{$\begin{array}{c}\begin{array}{c}\text { Kadar Kesadahan } \\
(\mathrm{CaCO})\end{array} \\
\text { Setelah Perlakuan }\end{array}$}} & \multirow{3}{*}{$\begin{array}{c}\text { Efektivitas } \\
\text { Penurunan } \\
(\%)\end{array}$} \\
\hline & & & & \\
\hline & & Kontrol & $\begin{array}{c}\text { Zeolit- } \\
\text { Karbon } \\
\text { Aktif }\end{array}$ & \\
\hline \multirow{3}{*}{160,24} & 1 & 109,76 & 131,71 & 17,8 \\
\hline & 2 & 113,05 & 87,80 & 45,2 \\
\hline & 3 & 124,02 & 109,76 & 31,5 \\
\hline \multicolumn{2}{|c|}{ Rata-Rata } & 115,61 & 109,75 & 31,5 \\
\hline
\end{tabular}

\section{B. PEMBAHASAN}

Sumber air yang digunakan oleh masyarakat di Kampung Sapiria berada dalam kondisi lingkungan yang padat dan berada dekat dengan kawasan rawa-rawa sehingga hal ini dapat mempengaruhi kualitas air bersih seperti tingginya kadar kesadahan pada air sumur gali yang digunakan oleh masyarakat di wilayah tersebut.

Kesadahan atau kekerasan (hardness) air berbeda dengan keasaman air, sekalipun keduanya erat kaitannya.Keduanya dapat dibedakan dengan mudah.Air asam biasanya menunjukkan reaksi lunak, sedangkan air sadah biasanya keras.Oleh karena itu, kesadahan air sering disebut kekerasan air (hardness). (Ghufran et.al.,2010)

yaitu zeolit dan karbon aktif dimana media Zeolit mempunyai beberapa sifat antara lain mudah melepaskan air akibat pemanasan, tetapi juga mudah mengikat kembali molekul air dalam udara lembab. Oleh karena sifatnya tersebut, zeolit banyak digunakan sebagai bahan pengering. Sifat ini pula yang menyebabkan zeolit dimanfaatkan untuk melunakkan air.(Kusnaedi, 2010)

Karbon aktif dipilih karena memiliki sejumlah sifat kimia maupun fisika yang menarik, di antaranya mampu menyerap zat organik maupun anorganik, dapat berlaku sebagai penukar kation, dan sebagai katalis untuk berbagai reaksi. Karbon aktif adalah sejenis adsorben (penyerap), berwarna hitam, berbentuk granul, bulat, pellet ataupun bubuk. Jenis karbon aktif tempurung kelapa ini sering digunakan dalam proses penyerap rasa dan bau dari air, dan juga penghilang senyawa-senyawa organik dalam air.(Mifbakhuddin, 2010)

Penelitian ini menggunakan media dengan ketebalan $60 \mathrm{~cm}$ dengan aliran secara up flow. Hal ini mengakibatkan adanya perbedaan keefektifan dari kedua media tersebut.

Hasil pemeriksaan kadar kesadahan $\left(\mathrm{CaCO}_{3}\right)$ air sumur gali di Kampung Sapiria, Kota Makassar menunjukkan hasil yang rendah sebelum dilakukan perlakuan filtrasi yaitu 160,24 $\mathrm{mg} / \mathrm{l}$ ini menunjukkan bahwa kadar kesadahan tersebut tidak melewati ambang batas yang diperbolehkan yaitu $500 \mathrm{mg} / \mathrm{l}$. Berbeda dengan hasil pemeriksaan uji pedahuluan yang dilakukan oleh penelitian dimana hasil yang didapatkan yaitu $548,8 \mathrm{mg} / \mathrm{l}$.

\section{Penurunan Kadar Kesadahan $\left(\mathrm{CaCO}_{3}\right)$} melalui Pengolahan Filtrasi Zeolit

Pada penelitian ini telah dilakukan perlakuan atau intervensi terhadap media filter zeolit didapatkan hasil yaitu rata-rata yaitu $76,82 \mathrm{mg} / \mathrm{l}$ kadar penurunan dengan tingkat efektivitas 52,05\%. Pada penelitian dilakukan, kadar Kesadahan yang didapatkan tidak melebihi dari ambang batas, tetapi dari hasil pemeriksaan menunjukkan bahwa media zeolit dapat menurunkan kadar kesadahan.

Zeolit adalah silikat hidrat yang mengandung ion-ion natriun dalam jumlah yang cukup banyak, berbentuk granula dan tidak larut dalam air. Air sadah yang dialirkan melalui kolom zeolit akan mengalami pertukaran ion-ion, yaitu $\mathrm{Ca}$ dan $\mathrm{Mg}$ dalam air dengan ion $\mathrm{Na}$ dalam zeolit. Hal tersebut berlangsung terus sampai pada saat kolom 
Jurnal Sulolipu : Media Komunikasi Sivitas Akademika dan Masyarakat

Vol. 20 No.12020

e-issn : 2622-6960, p-issn : 0854-624X

zeolit menjadi jenuh, tidak mampu lagi mengadakan pertukaran ion-ion. Agar zeolit dapat aktif lagi, zeolit dapat dibasuh atau dialirkan garam kapur sehingga pertukaran ion-ion natrium dalam air dapat masuk ke dalam zeolit untuk mengganti kedudukan ionion Ca dan Mg. (Ronny, 2016)

2. Penurunan Kadar Kesadahan $\left(\mathrm{CaCO}_{3}\right)$ melalui Pengolahan Filtrasi Karbon Aktif

Pada penelitian ini telah dilakukan perlakuan atau intervensi terhadap media filter karbon aktif didapatkan hasil yaitu ratarata yaitu $74,86 \mathrm{mg} / \mathrm{l}$ dimana kadar kesadahan mengalami peningkatan sehingga keefektifan dari media karbon pada penelitian ini yaitu $53,27 \%$.

Karbon aktif sangat berpengaruh terhadap penurunan kesadahan karena sifat dari masing - masing bahan filter tersebut dapat menurunkan kesadahan. Seperti yang dikatakan oleh Mulyani (2017), adsorpsi karbon aktif juga dapat diaplikasikan untuk proses penyerapan kation-kation logam terlarut $\mathrm{Ca}^{2+}$ dan $\mathrm{Mg}^{2+}$ yang terkandung dalam air. Selain prosesnya yang mudah dan cepat, penggunaan karbon aktif juga dapat diregenerasikan jika kondisi permukaannya telah jenuh oleh pengotor.

Karbon aktif yang berwarna hitam, tidak berbau, tidak berasa, dan kelebihan dari karbon aktif ini mempunyai daya serap yang jauh lebih besar dibandingkan dengan karbon yang belum menjalani proses aktivasi, serta mempunyai permukaan yang luas, yaitu antara 300 sampai $2000 \mathrm{~m} / \mathrm{gram}$. Luas permukaan yang luas disebabkan karbon mempunyai kemampuan menyerap gas dan uap atau zat yang berada didalam suatu larutan. Sifat fisik karbon aktif yang dihasilkan tergantung pada kekuatan daya tarik molekul penjerap maka terjadi proses absorpsi dari bahan yang digunakan, misalnya, tempurung kelapa menghasilkan arang yang lunak dan cocok untuk menjernihkan air, yaitu proses penyerapan zat - zat yang akan dihilangkan oleh permukaan arang aktif, termasuk $\mathrm{CaCO}_{3}$ yang menyebabkan kesadahan. Adsorpsi kimia adalah merupakkan hasil interaksi kimia sangat bervariasi dan ikatan kimia sebenarnya tidak benar - benar terbentuki tetapi kekuatan adhesi yang terbentuk lebih kuat di banding dengan daya ikat penyerap fisika.Panas adsorpsi kimia lebih besar di banding dengan adsorpsi fisika $( \pm 10-100$ $\mathrm{kkal} / \mathrm{mol}$ ) (Mifbakhuddin, 2010)

\section{Penurunan Kadar Kesadahan $\left(\mathrm{CaCO}_{3}\right)$ melalui Pengolahan Filtrasi Zeolit - Karbon Aktif}

Pada penelitian ini telah dilakukan perlakuan atau intervensi terhadap media kombinasi filter zeolit-karbon aktif didapatkan hasil yaitu rata-rata yaitu 109,75 mg/l dimana kadar kesadahan mengalami penurunan sehingga efektifitas dari media kombinasi pada penelitian ini yaitu $31,5 \%$.

Hal ini membuktikan ketebalan media filter pada media tunggal maupun kombinasi merupakan salah satu yang mempengaruhi keefektifan penurunan kadar kesadahan. Pada filtrasi menggunakan media tunggal zeolit terjadi penurunan yang lebih tinggi dibandingkan dengan filtrasi menggunakan kombinasi media zeolit - karbon aktif dengan ketebalan $30 \mathrm{~cm}: 30 \mathrm{~cm}$. Hal ini dikarenakan filtrasi dengan media tunggal zeolit dengan ketebalan $60 \mathrm{~cm}$ lebih maksimal dalam proses penyerapan dan pertukaran ion $\mathrm{Ca}$ dan $\mathrm{Mg}$ dari air ke media. Apabila dibandingkan dengan filtrasi menggunakan susunan zeolit dan karbon aktif dengan ketebalan $30 \mathrm{~cm}: 30 \mathrm{~cm}$ proses penyerapan dan pertukaran ion belum maksimal. Pada filtrasi dengan kombinasi zeolit - karbon aktif, air bagian bawah terjadi proses penyerapan dan pertukaran ion, sedangkan yang bagian atas hanya terjadi proses penyerapan ion saja. Hal tersebut menyebabkan proses pertukaran ion tidak maksimal sehingga hanya setengah dari ion $\mathrm{Ca}$ dan $\mathrm{Mg}$ yang terkandung dalam air sadah yang ditukar dengan ion $\mathrm{Na}$ yang berasal dari zeolit. Sedangkan apabila di filtrasi dengan media tunggal zeolit, proses penyerapan dan pertukaran ion $\mathrm{Ca}$ dan $\mathrm{Mg}$ dapat terjadi pada seluruh air yang berada dalam bak filter.

\section{KESIMPULAN DAN SARAN}

\section{Kesimpulan}

Berdasarkan hasil analisa pembahasan Aktivasi Zeolit Dan Karbon Aktif Dalam Menurunkan Kesadahan Air Di Kampung Sapiria Kota Makassar, maka dapat disimpulkan bahwa :

a. Media zeolit efektif dalam menurunkan kesadahan dengan rata-rata efektivitas yaitu $52,05 \%$ dengan hasil rata-rata penurunan dari $76,82 \mathrm{mg} / \mathrm{l}$

b. Media karbon aktif tidak efektif dalam menurunkan kesadahan karena mendapatkan hasil minus yaitu 53,27 
Jurnal Sulolipu : Media Komunikasi Sivitas Akademika dan Masyarakat

Vol. 20 No.12020

e-issn : 2622-6960, p-issn : 0854-624X

$\%$ dengan hasil rata-rata peningkatan $74,86 \mathrm{mg} / \mathrm{l}$.

c. Media kombinasi zeolit - karbon aktif efektif dalam menurunkan kesadahan dengan rata-rata efektivitas yaitu $31,5 \%$ dengan hasil rata-rata penurunan dari $109,75 \mathrm{mg} / \mathrm{l}$.

\section{Saran}

Bagi masyarakat yang ingin menggunakan proses pengolahan ini,

\begin{abstract}
disarankan untuk menggunakan satu media saja dalam proses pengolahan dengan meggunakan media zeolit disbanding menggunakan karbon aktif maupun media kombinasi untuk menurunkan kesadahan. Selain itu, dengan menggunakan satu media masyarakat dapat meminimalisir pengeluaran biaya.
\end{abstract}

\section{DAFTAR PUSTAKA}

Alamsyah, Sujana. 2007. Merakit Sendiri Alat Penjernih Air. Jakarta: Kawan Pustaka.

Asmadi, Khayan, Heru Subaris Kasjono. 2011. Teknologi Pengolahan Air Minum.Yogyakarta: Gosyen Publishing.

Effendi, Hefni. 2003. Telaah Kualitas Air. Yogyakarta: Kanisius.

Ghufran M. H. K. K. dan Andi Baso Tancung.2010. Pengelolaan Kualitas Air Dalam Budidaya Perairan. Jakarta: Rineka Cipta

Kodoatie, Robert J. 2012. Tata Ruang Air Tanah. Yogyakarta: Andi.

Kusnaedi.2010. Mengolah Air Kotor Untuk Air Minum. Jakarta: Penebar Swadaya.

Mifbakhuddin. 2010. Pengaruh Ketebalan Karbon Aktif Sebagai Media Filter Terhadap Penurunan Kesadahan Air Sumur Artetis. Semarang: Vol 5 (2).

Mulyani, Happy. 2017. Penuntun Praktik Analisis Dan Optimasi System Penyehatan Air Minum, Yogyakarta: Pustaka Pelajar.

Republik Indonesia. 2017. Permenkes Nomor 32 tentang Standar Baku Mutu Kesehatan Lingkungan dan Persyaratan Kesehatan Air untuk Keperluan Higiene Sanitasi, Kolam Renang, Solus Per Aqua, dan Pemandian Umum.Kementerian Kesehatan Republik Indonesia. Jakarta.

Ronny. 2016. Penyehatan Air. Makassar: Politeknik Kesehatan Kemenkes Makassar

Wibowo, Adik. 2014. Metodologi Penelitian Praktis.Jakarta: Rajawali Pers. 